\title{
CLINICAL EXPERIENCE IN DENGUE: EXPERIENCE OF SPECIALIZED SERVICE
}

\author{
Luiz José de SOUZA(1) \& Marcos BOULOS(2)
}

Although known for centuries, the infection by dengue virus is starting to exhibit different and more exuberant manifestations from the previously known forms from the middle of last century with the description of the hemorrhagic form of the disease.

The World Health Organization, aiming to standardize the different manifestations of dengue fever, has proposed a classification that would not only standardize the information, but mainly suggest actions to reduce the risk of death by this disease.

Despite the importance and need for guidance on the different clinical forms and procedures to be instituted, new manifestations, unexpected and expected, of dengue began to emerge with the spread of disease.

Different studies have pointed to regional differences regarding the clinical manifestations due to not only the prevalent serotype, but also the genetic polymorphism that can provide protection and also induce more severe forms of disease ${ }^{8}$.

The pattern of dengue prevalence among children, so common in regions where this disease is endemic for a long time, began to emerge in the Brazilian population in places where infection has occurred annually.

We present here the experience from a healthcare center providing assistance to patients with dengue in Brazil, which demonstrates the data exposed above.

The Reference Center of Dengue (Centro de Referência da Dengue, $C R D$ ), located in the city of Campos dos Goytacazes, unique in the country, is important for the population of this city and neighboring cities due to the high incidence of dengue in this region, and also contributing to a better understanding of dengue in Brazil and suggesting new approaches to provide care to a patient affected by this virus.

In 2010, CRD provided assistance to children which represented $11.44 \%$ of cases of dengue and in 2011, the cases in children up to 14 years were $14.99 \%$ by September. This data indicates worsening of this disease in younger children in the near future.

The clinical signs are always initiated by fever, headache, myalgia, anorexia, retro-orbital pain, nausea, prostration, vomiting, diarrhea and rash in lower percentage.
In the second or third day after the onset of symptoms, warning signs of hemorrhagic dengue appears in severe cases: abdominal pain, severe prostration, persistent vomiting and hypotension, which are conditions that require more vigorous action by doctors and other healthcare professionals.

These conditions, based on the pathophysiology of the dengue fever, occur due to increased vascular permeability with consequent leakage of liquids, dehydration, hemoconcentration, conditions which must be reversed immediately with intravenous hydration based on crystalloid solutions (saline or Lactated Ringer), introduced at high rates on the basis of $20 \mathrm{~mL} / \mathrm{kg} / \mathrm{h}$ and lower rates in order to stabilize the patient during hospitalization.

In the 2010 survey, based on medical records from 206 patients aged over 13 years, we observed the presence of serositis (pleural effusion and ascitis) in 55 patients, i.e., more than $25 \%$ of the hospitalized cases of dengue.

There was a difference in relation to pediatric patients. In adult patients with serositis, $95 \%$ of the cases were due to secondary infection, while children with serositis progressed to shock and death, and this was due to the primary form of dengue.

Importantly, at the time these observations were seen, serotype 2 infection prevailed in the region, which was pointed by several studies as the cause of the most severe forms of dengue.

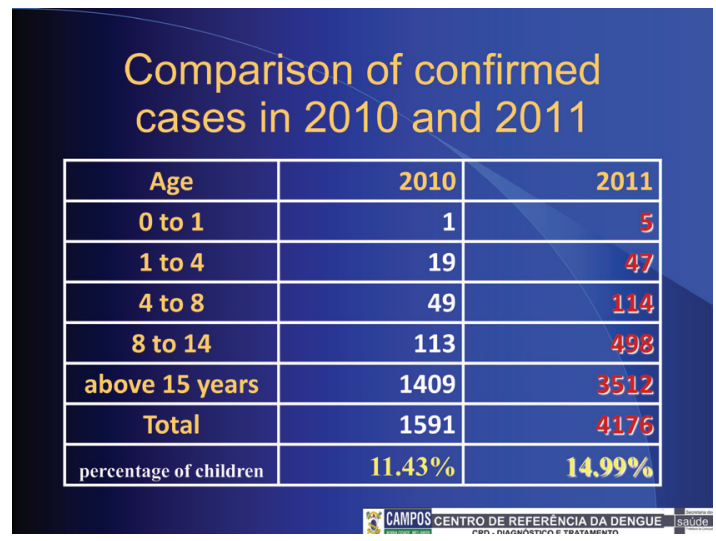

Presented at the I International Symposium on Dengue of the School of Medicine University of São Paulo on October 6, 2011.

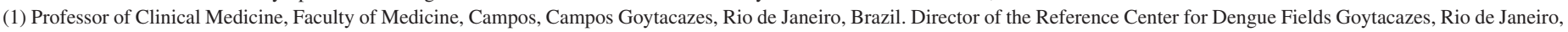

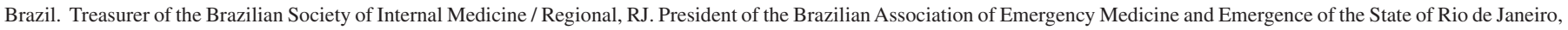
Brazil. Specialist in Internal Medicine and Emergency Medicine.

(2) Department of Infectious Diseases, Faculty of Medicine, University of São Paulo. E-mail: mboulos@usp.br 
Corroborating those studies, this worsening could be detected among children followed in this center which is probably due to their decreased immunity, what makes imperative the appropriate training and management of these patients by pediatricians.

A finding that deserves mention is the presence of thrombocytopenia in 50 from 55 patients with serositis. Cases with comorbidity (chronic renal failure, heart failure, diabetes or obesity) received platelet transfusion, which did not avoid events of bleeding.

A protocol for diagnosis was standardized with some nonspecific tests, such as CBC, erythrocyte sedimentation rate (ESR) and transaminases. Our observations suggest that leucopenia and not increased or reduced ESR represent indication for dengue diagnosis. Based on our observation, reduced ESR is more frequent among the more severe forms of the disease.

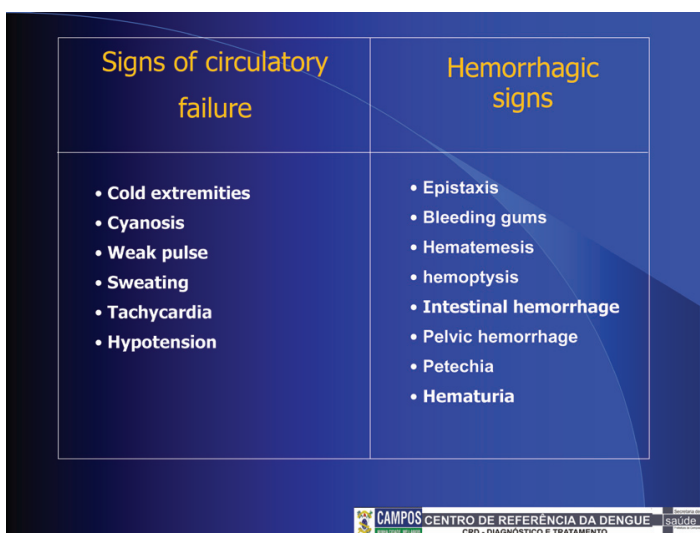

Ideally, the NS1 antigen assay should be requested from the $2^{\text {nd }}$ to $4^{\text {th }}$ day after onset of symptoms. In severe cases, it is very important to keep serum collected by the $5^{\text {th }}$ day for determination of C-reactive protein (CRP) and assessment of the circulating serotype in cases of deaths.

Serology (antibody measurement) should be only made after the $8^{\text {th }}$ day of onset of symptoms.

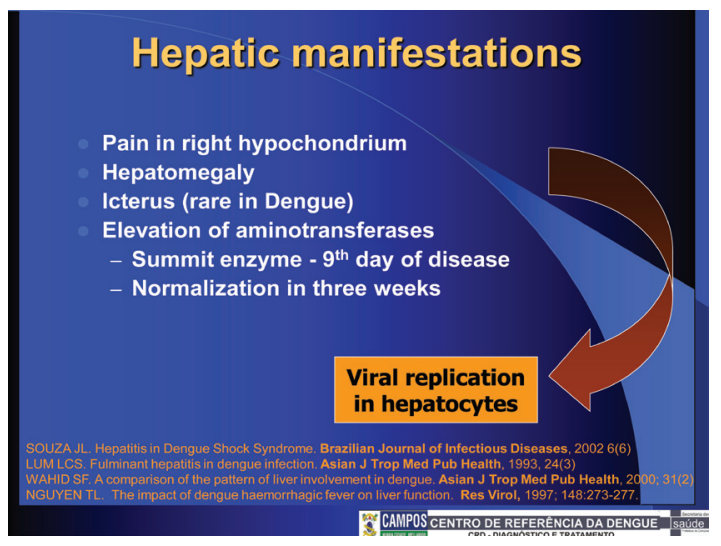

It is important to highlight that atypical clinical manifestations of dengue have been found, such as: involvement of the nervous system, heart conditions, peripheral neuropathies, purpura, ascitis, acute abdomen and liver abnormalities.

Liver abnormalities are quite frequent with high levels and the dosage of aminotransferases has been an important prognostic factor in our observations.

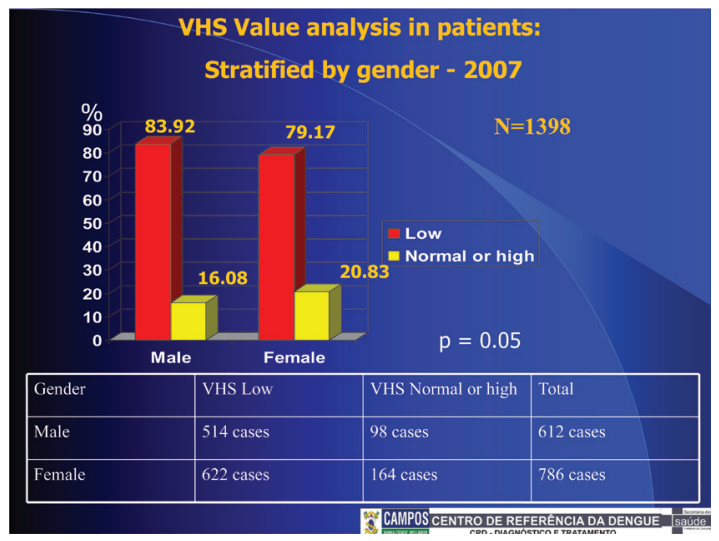

The Reference Center of Dengue (CRD) is important not only in the diagnosis and treatment of patients, but also in the assistance to combat the vector.

The following are positive points for CRD:

1. Centralization of information with improved notification.

2. Early notification for the department in charge to control vector.

3. Continuing epidemiological surveillance.

4. Early and accurate diagnosis.

5. Patients are monitored and thus, deaths are avoided.

The organization of care is paramount to achieve better results in the management of patients with dengue bringing efficiency in the differential diagnosis, which is quite broad.

The poor infrastructure for vector control primarily due to: low synchrony between cities, high rate of vectorial movement, unstructured and anarchic urban centers, underreporting of cases, errors in diagnosis, poor basic sanitation, lack of urban planning, inadequate management of solid waste (garbage), deterioration of public health infrastructure, leads to the consequent absence of proper control of the mosquito and non-eradication of outbreak foci.

Other social factors, such as unemployment, violence and educational deficiency, common in the country as a whole with special emphasis in the area we work are obviously associated with the difficulties of controlling dengue in our area.

Although the studies with vaccines protecting against all four serotypes are in advanced stages, which may represent an important measure to reduce dengue and risks arising from it, it could probably take several years to be used.

The circulation of the four serotypes (1, 2, 3 and 4) and the reintroduction of these serotypes, in different states of our country, indicate that the mortality by dengue fever is expected to increase, representing a real risk to public health in Brazil. 
In summary, the actions taken at CRD allowed not only to provide quality action to assist people with dengue fever, but also to propose simple laboratory markers to predict cases with more severe progression of the disease, especially in children.

\section{REFERENCES}

1. George R, Liam CK, Chua CT, Lam SK, Pang T, Geethan R, et al. Unusual clinical manifestations of dengue infection. Southeast Asian J Trop Med Public Health. 1988;19:585-90.

2. Lum LCS, Lam SK, George R, Devi S. Fulminant hepatitis in dengue infection. Southeast Asian J Trop Med Public Health. 1993,24:467-71.

3. Nguyen TL, Nguyen TH, Tieu NT. The impact of dengue haemorrhagic fever on liver function. Res Virol. 1997;148:273-7.
4. Nimmannitya S, Thisyakorn U, Hemsrichart V. Dengue haemorrhagic fever with unusual manifestations. Southeast Asian J Trop Med Public Health, 1987;18:398-406.

5. Organización Panamericana de la Salud. Dengue: guías de atención para enfermos en la región de las Americas. La Paz: Organización Panamericana de la Salud; 2010.

6. Souza JL, Carneiro HG, Souto Filho JTD, Souza TF, Cortes VA, Gicovate C, et al Hepatitis in dengue shock syndrome. Braz J Infect Dis., 2002;6:322-7.

7. Souza LJ, Gomes, CRP, Lopes AC, Souto Filho JTD, Souza TF, Cortes VA et al. Aspectos clínicos da dengue: novos conceitos. Rev Bras Clin Terap. 2002; 27:46-52.

8. Tan GK, Alonso S. Pathogenesis and prevention of dengue virus infection: state-ofthe-art. Curr Opin Infect Dis. 2009;22:302-8.

9. Wahid SF, Sanusi S, Zawawi MM, Ali RA. A comparison of the pattern of liver involvement in dengue hemorrhagic fever with classic dengue fever. Southeast Asian J Trop Med Public Health, 2000;31:259-63. 